\title{
Stad Strategies of Defending Self Image in the Public Speaking Delivered by Mr Tourism Sumatera Barat
}

\author{
1Putri Dian Afrinda; ${ }^{2}$ Diyan Permata Yanda \\ 1,2STKIP PGRI of West Sumatera, Padang, Indonesia \\ Email: 1putridian_afrinda@yahoo.com; 2diyan_yanda@yahoo.com
}

\section{Article Info \\ Article history: \\ Submitted April 13, 2018 \\ Revised December 5, 2018 \\ Accepted April 4, 2019 \\ Published April 4, 2019}

\section{Keywords:}

STAD Strategy,

Self-image,

Public Speaking

\begin{abstract}
This article aims to explain how public speaking strategies for $\mathrm{Mr}$. Tourism Sumatera Barat 2018 as a form of defending self image. The strategy that can be used is the strategy of telling Brown and Levinson about positive and negative faces. As the center of attention, a speaker must be able to maintain the face for an audience (audience) with the material presented. Public speaking training can be given in the form of material presentation and training using STAD type cooperative learning model. By using STAD type model, it is expected that the training participants can learn in their respective groups with directed instructors for the preparation of individual presentation. The results of the activities show that STAD model is effectively used to practice speech or public speaking. This is evident from the activity of the trainees following the material and confidence in public speaking.
\end{abstract}

\section{Corresponding Author:}

Putri Dian Afrinda,

STKIP PGRI of West Sumatera, Padang, Indonesia.

Email: putridian_afrinda@yahoo.com

\section{INTRODUCTION}

The Election of Mr. Tourism Sumatera Barat 2018 is a prestigious event to introduce West Sumatera tourism objects and arts nationally and internationally. The selected Finalists are talented people who have talent and concern for the environment, so it is expected to be the center of public attention. As the center of attention, the Finalist of Mr Tourism should not only have broad insight, but also have an ability to have a well interaction to others, communicative, persuasive and the ability to maintain self image.

The ability to maintain self-image in public speaking is the main thing that must be possessed by a speaker. The term self-image defending originally arose not from the term language, but from a case in court when a person wanted to defend his right before a judge, a rhetorical term which came to be known as the art of speaking. The art of speaking is indispensable in conveying the message as well as the aspirations to which the speaker is speaking. Speakers as the center of attention must have good speech. The ability to speak must be trained and developed because everyone is good at speaking but not everyone is good at attracting an audience so interested in what he wants to convey. One strategy that can be used is the strategy of telling Brown and Levinson about positive face defense and negative face.

Providing public speaking training to Finalists. Tourism Sumatera Barat 2018 is intended for participants to speak publicly correctly so that the purpose or message can be directly conveyed. Audience with various cultural backgrounds of course have different thoughts. Not all of them will 
immediately believe what the speaker says. It should be understood that public speaking is basically not to convey how to speak in public but what strategies are used so that all audiences believe in what is to be conveyed.

In order to implement this strategy of self defense in public, STAD type learning model is used, this model is chosen because it is expected to help improve the activity of public speaking and foster self confidence because it can be conditioned someone practice speaking in small groups and mutual helping each other. This is to train a person or group member to accept differences of opinion and endeavor to defend against friends of different backgrounds. Members in group teams may not end the activity before all members of the group have the opportunity to practice speaking, if any team members make mistakes then other members are entitled to correct and explain the right way. In this process, the training instructor can supervise and provide guidance in case of difficulties in each group. There are six phases of STAD model implementation in the implementation of self defense strategy training in public speaking, among which (1) conveys goals and motivates, (2) presents information, (3) organizes trainees into small groups, 4) assist group work in training, (5) evaluation, (6) reward.

The choice of public speaking strategy is also based on the assumption that previous research contained in the ICLA-6 proceedings indexed Atlantis with ISBN: 978-94-6252-444-6 entitled Turn Taking Strategy to Maintain Women's Self Image in Novel Coffee Quiz Written by Yetti AKAen proved can further explain the meaning of speech against his opponent to cover his lack of self and to maintain the image of himself as a woman.

The choice of STAD model in training implementation is based on the assumption that this model is effectively used to improve the ability of public speaking. This is because the STAD model in the previous research, in accordance with the results of the study entitled Effect of Cooperative Learning Model Type Student Team Achievement Division (STAD) on Understanding Poetry Skill. Contained in the proceedings ICLA-6 indexed Atlantis dengan ISBN: 978-94-6252-444-6 proved to improve the ability to understand poetry. Based on these assumptions, if the STAD model can contribute to improving students' understanding of poetry, this model is also expected to understand the ability of trainees in speaking skills, hereinafter referred to as public speaking.

Based on the above background, then the formulation of this article is described as follows. (1) How is the strategy of maintaining self-image in public speaking? (2) How is the application of STAD model in public speaking training?

\section{THEORY AND METHODS}

\section{A. Understanding Self Image}

Lots of evidence suggests that a conditioned, programmed, directed, self-directed self-image controls success by starting honestly with itself. The phenomenon of building a self-image today is just the opposite of many who are racing to build self-image (self image) for a certain prestige, ambition and purpose by deceiving himself. To him he dared to lie let alone to others of course the greater the lie. Self image (self image) is one of three elements of self concept (self concept). Selfimage or often called self-reflection (inner mirror) shows how one sees one's self and his or her own opinion. According to Syarief (2005:42) a negative self-image is called bad self image. This negative self-image arises from the closest environment of the family. The family will determine whether to produce a positive or negative brand image. The continuity of a communication event is strongly influenced by the polite or not a speech. A polite speech will result in the convenience of communicating between speakers and opponents of speech. Conversely, impolite speech will result in discomfort between speakers and opponents. Even speakers can be considered unethical in speaking.

Ethics in language is important in communication. We can interpret ethics as a science of something good and bad or about rights and obligations. Speakers will be considered ethical in the language when it can communicate with good speeches. Masinambow (in Chaer and Agustina, 2010:172) argues that the language system has a function as a means of human interaction in 
society. In language behavior should be accompanied by the norms that apply in a culture. The system of behavior in the language that following cultural norms is called ethics in the language. Language ethics is a subsystem of culture. This can be proven from a person's ability to be measured through his knowledge of a culture in a society in which he lives. Through the culture learned, he/she will be able to easily use the language in accordance with the language or ethics of the language applicable in that society. Ethics is closely related to the existence of a community group. Therefore, language ethics should be owned by a person or community group. Through language, one will know the social and cultural status in society so that it can facilitate in choosing or using the language appropriately and in context.

In applying the ethics of language, one should be given knowledge of the social rules of language, such as who speaks, with what language, to whom, about what, when, where, and what purpose. By knowing these rules a person or society will be easier in choosing words in communicating. As Hymes argues (in Chaer and Agustina, 2010: 172) that speech events must meet eight components, including setting and scane, that is with respect to time and place of speech. Participant, the party involved in the conversation. Ends, ie intent and purpose of speech. Act sequence, ie speech form and speech content. Key, ie tone, manner and spirit when a message is delivered. Instrumentalities, ie the language path used. Genre, ie the form of delivery. The choice of words used should also be considered. For example, when greeting an older, equal, younger, or child. Its social status is higher, equal, or lower. The situation is formal or informal, intimate or unfamiliar. Spoken by man or woman, already known or not. In addition to social aspects, the thing to be considered in the ethics of language is timeliness. That is, by knowing when it's time we talk and listen, then someone or society will respect each other in interacting or communicating.

From the above explanation can be concluded that the ethics of language is a behavior in interacting and communicating using the language. Behavior in the language is governed by the norm, the ordinance in considering the context in speaking.

\section{B. Mr. Tourism}

Mister Tourism Indonesia (previously named Mister Tourism Indonesia) is the annual national man contest event that has been going on since 2016 under Yaya-san Mister Tourism Indonesia. The winners will represent Indonesia at the internationals men contest Mister Tourism International, Mister Continental Tourism, Mister Culture World and Mister United Continents. Mister Tourism West Sumatera is the annual event of the son of Indonesian tourism conducted in the western provincial level under the auspices of GKC Prodaction.Finalist institution from West Sumatera who was sent to follow the event of Mister Tourism at the level of National 2017 is Mr. Alfin Samister. Mr. Alfin Samister was a Finalist representing West Sumatera at the Mister Tour Indonesia and defending Mr. Marine Tourism In Indonesia.

FoundationMister Tourism Indonesia/YPPI (formerly known as Mister Tourism Indonesia organization) was officially established on May 30, 2015. FoundationMister Tourism Indonesia is the first and only Foundation as the organizer of the election of the special National Tourism Ambassador for the category of Men officially registered and received direct support from the Government of Indonesia through the Ministry of Tourism of the Republic of Indonesia for the Mister Tourism Indonesia event organizer with the Reminder of the Ministry of Tourism No: HK.505/3/4/DP3N/KEMENPAR/2015 which also expressed the hope that all parties to support and participate in succeeding Mister Tourism Indonesia activities organized by FoundationMister Pa-tourism Indonesia.

In addition, to getting support from the Ministry of Tourism of Indonesia, Mister Tourism Indonesia also received the confidence to participate in the success of several pro- grams of the Government of Indonesia, especially in the field of promotion, cultural preservation, tourism and the environment and establishing cadre high achievers who have a passion for Culture, Tourism and the Environment. In addition to serving in several job programs in the field of promotion, education and social activities under the Foundation of Mister Tourism Indonesia, as well as other 
national arena, Mister Tourism Indonesia is elected will also get the responsibility and honor to represent Indonesia to the arena International.

Mister Tourism Indonesia (formerly Mister Tourism Indonesia) is the annual national men's contest event that has been going on since 2016 under Foundation Mister Tourism Indonesia. The winner will represent Indonesia at the internationals men contest Mister Tourism InternationalMister Continental Tourism Mister Culture World and Mister United Continents. The last degree holder is Ryan Ramadhan from North Sumatera. In 2017 FoundationMister Tourism Indonesia has created a new male contest Mister Earth Indonesia where the winners will represent Indonesia In the contest of the international male contest Mister Earth. Mister Earth Indonesia contest itself in 2017 will be held simultaneously with Mister Tourism Indonesia.

\section{Mister Earth}

Mister Earth is an annual environmental-themed environmental contest-which promotes awareness and sensitivity to environmental issues. This contest was formed in 2001 in the Philippines. Since then, Mister Earth has become one of the beauty contests international with the Beauties for a Cause tagline. The contest title holder represents one year of his tenure to promote a specific project and often address environmental issues and other global issues through tours to various countries, tree planting, social campaigning, reef care corals, media gatherings, environmental exhibitions, eco-friendly fashion show, and other environmental-themed activities. Since it was first held, most contests were held in the Philippines, either in October or November, and broadcast nationwide through ABS-CBN and Studio 23 with international delayed shows in over 80 countries through Star World and The Filipino Chan?

\section{Mister Culture Word}

Mister \& Miss Culture World Pageant was founded in 2014 by Saidali Abdilla Jr., a contest aimed at promoting her culture and preservation on the global stage. The first and second editions of the contest were held in Kota Kina on Sabah Island, Malaysia. Previous winners for 2015 were Arnepha Abdusalam from the Philippines as Miss Culture World and Mashoor Awang from Malaysia as Mister Culture World. The winner is Bob Royo from the Philippines as Mister Culture World 2016 and Hnin Wutyee Win of Myanmar as Miss Culture World 2016. This year 2017, this contest will let the Finalists experience the beauty of the Philippines. Delegates will also be exposed to the world-famous hospitality by enjoying local cuisine and traditional cuisine. The town of Bacolod in Negros Occidental will be one of the LGU's hosts for an international stage. The Finalists participated in an advocacy tour across the province, having a game featuring larong snapshots, enjoying local flavors through specially prepared food parties and a fashion show featuring local designers

\section{Mister International}

Mister International is one of the male election contests held since 2006. This contest is the third largest male contest after Manhunt International and Mister World. The event was initiated by Alan Sim, president of Mister Singapore Organization in 2006, and followed by participants from several countries (including Indonesia). The event was held by Mister Singapore Corp. who also holds the Mister Singa ore election each year. Mister International consists of 2 seasons, Preelimination and Final. In the Pre-elimination round, the assessed aspects include participant's regional attire, swimwear and formal attire. In the final round, there will be 15 participants who will compete for Mister International. In addition it will be selected also Best National Costume, Mister Photogenic, Mister Congenationity and Mister Spirit.

\section{Mister World}

Mister World is a men's contest that stands under the auspices of Miss World Organs-tion, the same organization as Miss World. The contest was first held in 1996 but has not been routinely held every year, and since the year 2010 is regularly held every 2 years. Current title holder Rohit Khandel from India, who won the contest on July 19, 2016 and held in Southport, England. Generally, the winner of Mister World will stay in London during her tenure.

5. Men Universe Model

The Men Model Universe is actually the fourth largest male contest in the world after Manhunt International, Mister International and Mister World. This contest has been held since 2008 in Dominican Republic. This contest is also different from Mr. Universe (bodybuilding 
contest), and also not one organization with Miss Union. For Indonesia itself, only appear once in 2011, which represented from the winner of L-Men of the Year, Rikas Harsa. The Mister Universe Model was started in 2008 by Robert Flores designer, with a vision of promoting a world-class male model. Since its inception, the contest has been held in the Dominican Republic.

\section{Understanding Public Speaking}

Dunar (2014:6) suggests that public speaking to speak publicly correctly so that messages can be clearly conveyed and speech objectives can be obtained immediately. Furthermore, Dunar (2014:12) explains the main basis of public speaking, among others: (1) Honest, do not fabricate facts when talking, because when you are known not to speak the truth, it is difficult to get trust again from the audience; (2) The right attitude, proper body language makes you believable; (3) Be interested in the subject matter, the more excited you are when talking about your material, the more appealing it will be to your appearance; (4) Be open to yourself, do not be allergic to criticism, keep improving appearance to near perfection. Public speaking uses include presentations, speaking at meetings, giving speeches, radio broadcasters, master of ceremonies, moderators, TV presenters, etc. (Dunar, 2014:9). For Mr. Tourism's use of public speaking is to speak to convince juries and audiences as the competition progresses and as the ability to support arguments as the ultimate foundation of thoughtful thinking.

Olii suggests that (2008: 2) the term public speaking originated from a rhetorical experts who interpret the same art (skill) berbicara or speech that has developed since the century BC. The real understanding of rhetoric is the expansion of the highest talents of man, namely the ratio and taste through language as the ability to communicate in the media of the mind. With rhetoric, leaders can conquer hatu and soul, or the ability to tinkle with, so that the decision can be accepted by employees or audience. Public speaking is considered as a means of communication because in a means of communication or a container rolling conversation requires feedback. In the container that shelter communicators, messages, and communicant. All of this will work through channels or channels called media. Public speaking presence in communication is as a communicator or public speaker. A communicator must have the ability to present ideas to the audience. On the occasion of advising, criticizing, voting and representing their organizations and making decisions, public speaking techniques are as important as the ability to dialogue with other individuals effectively.

Aristotle, who lived before Christ, wrote rhetoric (intelligence of speech) that there are three main points in the talk of the topic being discussed, who to talk to, and arranging in order of beginning, middle and end. These basic functions can make it easy to organize conversations that can help how to emphasize important points, can reduce unnecessary things, in order to retain audience interest in speaker messages. The basics will be easy to apply every public speaking, and automatically the basics will not be each other. Preparing the order of beginning, middle and end as the basis of speaking is as follows. (1) The first section serves to attract the listener's interest and introduce the topic being discussed. The goal is to make the listener interested to hear further conversation. (2) The middle section, serves to present the topic discussed, in more depth. This is where all the information is poured in support of the topic. This is where all the information is poured in support of the topic. The goal is to make the listener more interested to listen to the conversation to finish. (3) The final section, serves to summarize the topics discussed into reinforcing facts. The goal is that the listener is impressed by this closing piece, there are results, there is a continuation.

According to Jalaludin Rakhmat (in Olii, 2008:28) appear in public has the following purposes. (1) notify (informative) is intended to increase the knowledge of the listener. Communication is expected to get an explanation, interest and have an understanding of the issues discussed, such as notifying some provisions on the use of Indonesian national flag (PP No. 40/1958). (2) Influence (persuasive) is addressed to people who believe in something, do it or burn their spirits. Confidence, action and spirit are the expected form of reaction. (3) Entertaining (recreative), attention, fun, and humor are the expected reaction of listeners. The language is light, fresh and easy to digest.

Based on the above theory, then the implementation of community service activities followed by the Finalists Mr. Tourism Sumatera Barat 2018 with the theme of self defense strategy training 
in public speaking using STAD model has a purpose besides giving information also to influence others. Introducing tourism potential in Sumatera area and persuade to recognize more.

\section{Defending Strategy}

The word 'strategy' in the language courtesy strategy does not always mean conscious effort to behave politely, but also refers to routine language expressions and refers to speaking politely (Nadar, 2009:31). A self defense strategy is needed by the speaker in speaking so that the intentions he wishes to convey are well communicated while maintaining language decency. Leech (in Nadar, 2009:28) argues that in a society the role of manners is very important and necessary to explain the principle of cooperation. The intended strategy is a turning strategy of Brown and Levinson. Speaking strategies arespecific ways or speech-delivery techniques that speakers choose for different purposes and intentions by considering variousspeech situation factors. Brown and Levinson (1987) explain that language politeness or language courtesy refers to the conceptof face (face) (Afrinda, 2018).

In line with that, According to Yule (in Nadar, 2009:32) the underlying theory of language courtesy strategy is the concept of face 'face'. The concept of advance is important in the study of the use of language as a means of communication. Thus, there are two types of faces: negative face and positive face. The negative face is the desire of the individual so that his every desire is not obstructed by others, while the positive advance is the desire of every speaker to be accepted or liked by other parties. Brown and Levinson (in Nadar, 2009:35) explains that a number of actions are both at the same time violate both the negative face and positive face of the opponent said. Further Hayashi (in Nadar, 2009:35) classifies rejection as an action that can threaten positive and negative faces. Thus the strategy used to make a more polite refusal involves a positive politeness strategy that is to minimize the threat to the positive face of the opponent and also a negative propriety strategy. That is an attempt to reduce the level of violation against adversary negative opponent.

To reduce the disillusionment of the opponent, Brown and Levinson (in Nadar, 2009:43) offer the following strategies for actions that violate the positive face of the opponent, among others, as follows. Strategy 1: pay particular attention to the opponent. Strategy 2: exaggerate interest, approval, sympathy for the other person. Strategy 3: increase interest in the opponent. Strategy 4: using a marker that shows the similarity of identity or group. Strategy 5: seek and seek agreement with the other person. Strategy 6: avoid conflict with the other person. Strategy 7: presupposes or raises perceptions of a number of speakers and speakers' equations. Strategy 8: make a joke. Strategy 9: make the perception that the speaker understands the opponent's desire to speak. Strategy 10: make offers and appointments. Strategy 11: shows a sense of optimism. Strategy 12: trying to involve the opposite of speech and speaker in a particular activity. Strategy 13: give and ask the reason. Strategy 14: offer a reciprocal action that if the opponent says do X then the opposite said will do Y. Strategy 15: give sympathy to the opponent said.

\section{E. Application of STAD Type Model}

Application of STAD Type Model is expected to help Mr. Finalists. Tourism 2018 in understanding public materials Speaking given in training because in the process can be done through certain phases in stages and encourage confidence in their respective groups. This is in line with the process of group learning by students in lecturing activities. This STAD type cooperative learning model encourages students to be active in group discussions. Cooperation in groups in underdeveloped materials effect the understanding of individuals because after the group discussion will be tested individually. Each student will continue to collect assessment points both when working in groups and individuals. The results will be calculated and the highest score will be given a lesson. This model of learning is assumed to be appropriate for learning processes that require students' skill and skill, especially lecture materials that demand practice in addition to theory (Yanda, 2018).

Based on the above quotation, it is stated that STAD Model is essentially one of the models of group learning that expects the participants to be active in the discussion activities. Other group members can help their colleagues if they have difficulty. The results obtained from group discussions by each group are shown individually to be assessed and rewarded for the highest 
score. This research method iscontent analysis or content analysis. The data in this study is a speech delivered by Mr. Finalists. Tourism 2018. This research will contain data citations to illustrate the self-awareness of public speaking by using specific strategies. Data collection is done by recording the speech contained in the video recording during the research. That is, the data obtained based on observation/direct observation in the field or place of public speaking training took place.

According to Subroto, (1992:5) qualitative method is method of method of study or research method to a problem that is not designed or designed by using statistical method. In qualitative research, the paradigm or perspective used is a phenomenological perspective. That is, qualitative research seeks to understand the meaning of phenomena, events, and their relation to the people or societies studied in the context of life in the real situation (Maria Ana Widyaningrum1, Sumarlam2, 2017).

\section{FINDING AND DISCUSSION}

Based on the above theoretical description can be described analytical data discussion based on the theory of face threat strategies presented by Brown and Levinson; (2) public speaking function; and (3) speech events. The following will be described more fully. Brown and Levinson (in Nadar, 2009:43) offer the following strategies for actions that violate the positive face of the opponent are as follows.

\section{Strategy 1: pay particular attention to the opponent.}

Can be seen in the following data.

Why should we choose you as Mr. Tourism Sumatera Barat 2018? Because I have some personality in mister, manners, intellectual, sociable, energric, responsible. The function of public speaking based on the above data is to vote and represent the organization and make decisions. That is, the opponent attempted to vote by explaining that he deserved to be a mister.

Identify the speech events in the above data as follows. Setting and scane, which is related to time and place of speech progresses. Setting the data above held on February 17, 2018 at Ballroom Tjahaja Baru, Central Yamaha Padang road Damar No.57. Participant, the parties involved in the accounting of the data on the side of the jury and participants. Ends, the intent and purpose of the speech, the jury asks the participants to answer the questions given. Act sequence, namely the form of speech and the content of speech, the speech between the jury and the participants are related because of questions and answers. Key, ie tone, manner and spirit when a message is delivered. In the sentence the jury asked the participants to give answers that can convince the jury, while the Finalist's answer the pertanan show confidence by providing detail reasons. Instrumentalities, ie the language path used. Participant language is spoken language. Genre, ie the form of delivery. Conversations that take place in a formal atmosphere.

The above tutorials include a positive politeness strategy because the participant gives the opponent a chance to explain the reason. The use of such attention-giving strategies is used to protect the opponent's self-image in order to foster self confidence.

Strategy 2: exaggerate interest, approval, sympathy for the other person.

Can be seen in the following data.

If you are given a choice, what will you choose scissors or paper? What I choose is scissors because it can give two thoughts, whereas a knife is only one way and can hurt one another.

The function of public speaking based on the above data is to vote and represent the organization and make decisions. That is, the opponent said trying to give voice by giving answers from two options given.

Identify the speech events in the above data as follows. Setting and scane, which is related to time and place of speech progresses. Setting the data above held on February 17, 2018 at Ballroom Tjahaja Baru, Central Yamaha Padang road Damar No.57. Participant, the parties involved in the accounting of the data on the side of the jury and participants. Ends, the intent and purpose of 
speech, the jury asks participants to answer the questions given. Act sequence, namely the form of speech and speech content, namely the speech between the jury and the participants are related because of questions and answers. Key, ie tone, manner and spirit when a message is delivered. In the sentence the jury asked the participants to give an answer based on an analogy to the view or description of a particular object. While the Finalist's replies to the questions give the reason for the option of the question given. Instrumentalities, ie the language path used. Participant language is spoken language. Genre, ie the form of delivery. Conversations that take place in a formal atmosphere.

The above tutorials include a positive politeness strategy because the participant gives the opponent a chance to explain the reason. The use of such attention giving strategies is used to protect the opponent's self image.

Strategy 3: increase interest in the opponent.

Can be seen in the following data.

"Trying new things is a challenge for me. Therefore I am motivated to follow this event thanks"

The function of public speaking based on the above data is to provide a decision on the activities being undertaken at the time. Identify the speech events in the above data as follows. Setting and scane, which is related to time and place of speech progresses. Setting the data above was held on February 14, 2018 in LPMP State University of Padang. Participant, ie the parties involved in the speech that the data on his party that is Mr. Finalist participants. Tourism 2018 West Sumatera. Ends, ie intent and purpose of speech, ie the participants give a picture, his views on the activities that he will follow it. Act sequence, which is the form of speech and speech content, ie the participant's speech pertaining to the opinion of oneself. Key, ie tone, manner and spirit when a message is delivered. In the speech the participants gave the reason to follow the event held at that time. Instrumentalities, ie the language path used. Participant language is spoken language. Genre, ie the form of delivery. Conversations that take place in a formal atmosphere.

The above tutorials are included in the positive politeness strategy because participant opinion can increase the interest of the opponent.

Strategy 4: using a marker that shows the similarity of identity or group.

Can be seen in the following data.

"For I am aware that without the support of my parents will not be able to pass the limitations in life. One big tree will not stand firmly without a thousand or millions of roots below it. Likewise with my parents, without the support and prayers of my parents, I will not be like this now. Wasalam "

The function of public speaking based on the above data is to vote and represent the organization and make decisions. That is, speakers are aware of the many parties who have provided support so that speakers can take decisions such as following the event Mr. Tourism 2018. Identify the speech events in the above data as follows. Setting and scane, which is related to time and place of speech progresses. Setting the data above was held on February 14, 2018 in LPMP State University of Padang. Participant, ie the parties involved in the speech that the data on his party that is Mr. Finalist participants. Tourism 2018 West Sumatera. Ends, ie intent and purpose of speech, ie the participants give their opinions about things that have been achieved can not be separated from family support. Act sequence, namely the form of speech and speech content, namely the speech of participants with regard to opinion speakers. Key, ie tone, manner and spirit when a message is delivered. In the speech the participants express their opinions with enthusiasm. Instrumentalities, ie the language path used. Participant language is spoken language. Genre, ie the form of delivery. Conversations that take place in a formal atmosphere.

The above tutorials include a positive politeness strategy because the speaker realizes that the success achieved at that time is supported by the family.

Strategy 5: seek and seek agreement with the other person.

Can be seen in the following data. 
"I became more confident to appear in public. Getting new friends, new families, new relationships is a point that I love. My family conflicted with me since I followed the modeling world. With some demonstration and verification they finally allowed me to follow some of the activities as long as they were positive "

The public speaking function based on the above data is to vote and make decisions. This means that the votes given in the form of opinions on experiences that have been passed and decisions on the activities that are being undertaken at the time. Identify the speech events in the above data as follows. Setting and scane, which is related to time and place of speech progresses. Setting the data above was held on February 14, 2018 in LPMP State University of Padang. Participant, ie the parties involved in the speech that the data on his party that is Mr. Finalist participants. Tourism 2018 West Sumatera. Ends, ie intent and purpose of speech, ie the participants give a picture, his views on the activities that he will follow it. Act sequence, which is the form of speech and speech content, ie the participant's speech pertaining to the opinion of oneself. Key, ie tone, manner and spirit when a message is delivered. Key on the above data delivered speakers in a way that can convince the opponent he said. This can be proved by some of the achievements that speakers have attained. Instrumentalities, ie the language path used. Participant language is spoken language. Genre, ie the form of delivery. Conversations that take place in a formal atmosphere.

The above tutorials include a positive politeness strategy because the speaker's opinion seeks the persuasion of his opponent by giving an opinion picture of the experience he has ever lived.

Strategy 6: avoid conflict with the other person.

Can be seen in the following data.

"Peace be upon you, and Allah mercy and blessings. I am Egi Samister Finalist Mr. Tourism 2018 Representative of Ta-nah Flat. 2013 is the beginning I became Uda Tourism Ambassador Tanah Datar. Seir-ing the passage of time I was appointed by PEMDA Tanah Datar to become a radio broadcaster. My mama's message becomes the person responsible for your work and always the humble person "

The function of public speaking based on the above data is to vote and represent the organization and make decisions. This means the speaker gives a voice by explaining the course of his career in the world that ditekuni now. Identify the speech events in the above data as follows. Setting and scane, which is related to time and place of speech progresses. Setting the data above was held on February 14, 2018 in LPMP State University of Padang. Participant, ie the parties involved in the speech that the data on his party that is Mr. Finalist participants. Tourism 2018 West Sumatera. Ends, ie intent and purpose of speech, ie the participants give a picture, his views on the activities that he will follow it. Act sequence, which is the form of speech and speech content, ie the participant's speech pertaining to the opinion of oneself. Key, ie tone, manner and spirit when a message is delivered. Key on the above data conveyed speakers with confidence. Instrumentalities, ie the language path used. Participant language is spoken language. Genre, ie the form of delivery. Conversations that take place in a formal atmosphere.

The above texts include a positive politeness strategy because the speaker reinforces his opinion with the cover of a message from his parents.

Strategy 7: presupposes or raises perceptions of a number of speakers and speakers' equations.

Can be seen in the following data.

How Mister to promote tourism in West Sumatera to the international arena? I will promote the existing tourism in West Sumatera by using the sophistication of the internet. One of them with social media. With the media so-sial, everyone will know both local and international about tourism in Indonesia, especially in West Sumatera.

The function of public speaking based on the above data is to vote and represent the organization and make decisions. That is, the opponent said trying to give voice by explaining in 
detail the answer of the question the jury. Identify the speech events in the above data as follows. Setting and scane, which is related to time and place of speech progresses. Setting the data above held on February 17, 2018 at Ballroom Tjahaja Baru, Central Yamaha Padang road Damar No.57. Participant, the parties involved in the accounting of the data on the side of the jury and participants. Ends, the intent and purpose of speech, the jury asks participants to answer the questions given. Act sequence, namely the form of speech and speech content, namely the speech between the jury and the participants are related because of questions and answers. Key, ie tone, manner and spirit when a message is delivered. In the sentence the jury asked the participants to give the jury an acceptable answer in the judgment, while the Finalist's answer to the question indicates how far the Finalist's understanding of the question was given. Instrumentalities, ie the language path used. Participant language is spoken language. Genre, ie the form of delivery. Conversations that take place in a formal atmosphere.

The above tutorials include a positive politeness strategy because the speaker wants to know what strategy will be used by the Finalists as his opponent in order to promote Indonesian tourism in the eyes of the world. This strategy is suitable for generating perceptions of participatory equations.

Strategy 8: make a joke.

Can be seen in the following data.

Introduce, I am one of Mr. Finalists. Tourism 2018. If anyone needs my phone number, I'll give it later. However, in fact it is not my phone no-mor but my parents phone number is caused I myself do not memorize my hape number.

The function of public speaking based on the above data is to provide advice and voice and represent the organization. That is, the speaker seeks to explain his identity that is not far from the role of his parents. Identify the speech events in the above data as follows. Setting and scane, which is related to time and place of speech progresses. Setting the data above held on February 16, 2018 in LPMP State University of Padang. Participant, ie the parties involved in the speech that the data is his party that is the participant in this case is one of Mr. Finalists. Tourism 2018 West Sumatera. Ends, the intent and purpose of speech, ie the participants explain their identity. Act sequence, which is the form of speech and speech content, ie the participant's speech is related to self introduction. Key, ie tone, manner and spirit when a message is delivered. In the speech the participants introduced themselves with a bit of a joke for not memorizing the HP number. Instrumentalities, ie the language path used. Participant language is spoken language. Genre, ie the form of delivery. Conversations that take place in an informal atmosphere.

The above tutorials include the negative politeness strategy of not being able to protect his or her image in public. This can be proved by the reason stated directly that speakers do not memorize his cell number. So it can be concluded that the strategy to make a joke in public is not always able to protect the self-image because the impact is not always positive politeness. speak.

Strategy 9: make the perception that the speaker understands the opponent's desire to

Can be seen in the following quotation.

How do you preserve the culture of young people now?

\section{By familiarizing children with cultural games}

The function of public speaking based on the above data is to vote and represent the organization and make decisions. That is, the opponent said trying to give voice by explaining the answer to the question of the jury. Identify the speech events in the above data as follows. Setting and scane, which is related to time and place of speech progresses. Setting the data above held on February 17, 2018 at Ballroom Tjahaja Baru, Central Yamaha Padang road Damar No.57. Participant, the parties involved in the accounting of the data on the side of the jury and participants. Ends, the intent and purpose of speech, the jury asks participants to answer the questions given. Act sequence, namely the form of speech and speech content, namely the speech 
between the jury and the participants are related because of questions and answers. Key, ie tone, manner and spirit when a message is delivered. Messages conveyed speakers to the opponent he said by testing but with a relaxed tone. Instrumentalities, ie the language path used. Participant language is spoken language. Genre, ie the form of delivery. Conversations that take place in a formal atmosphere.

The above tutorials include the negative politeness strategy because the participant is directly concerned with questions that can compel the perception of the opponent. The use of this strategy can not protect the self image of the opponent because it does not provide opportunities, or options to the opponent he said.

Strategy 10: make offers and appointments.

Can be seen in the following quotation.

"Assalamualaikum wr.wb.introduce my name Sutan Oki Finalist Mr. Tourism Sumbar 2018 Dharmasraya representatives. Being a contractor and consultant is my ci-ta-ima from the first. Therefore I am majoring in Civil Engineering. During college I fill my free time in the world of modeling. At first I was scared because I did not have any background in the world. But after I live it I have a passion in that"

The function of public speaking based on the above data is to vote and represent the organization and make decisions. This means that the speaker tries to vote by explaining his or her uncertainty about something new. Identify the speech events in the above data as follows. Setting and scane, which is related to time and place of speech progresses. Setting the data above was held on February 14, 2018 in LPMP State University of Padang. Participant, the parties involved in the discussion on the data that his party ie participants. Ends, ie intent and purpose of speech, ie participants sharing experiences about similar events that are being done at that time. Act sequence, ie speech form and speech content. The form of speech on the above data is to discuss about the level of education taken effect on the ideals, but not related to the hobby speakers. Key, ie tone, manner and spirit when a message is delivered. Speakers convey the message with passion and without hesitation. Instrumentalities, ie the language path used. Participant language is spoken language. Genre, ie the form of delivery. Conversations that take place in a formal atmosphere.

The above tutorials include a positive politeness strategy because the speaker can share his experience that success can be achieved even if it is not in accordance with the ideals and levels of education. The use of bidding and appointment strategies can be used to maintain the speaker's self image.

Strategy 11: shows a sense of optimism.

Can be seen in the following quotation.

"Assalamualaikum wr.wb. I am Hary Julianeka Finalist Mr. Tourism Sumbar 2018. I am representative of Pesisir Selatan Regency. Family is the greatest motivation in my life. Without family I will not go this far. I really love both my parents. Because parents I have given moral and material, love and protection. My greatest motivation in this life is My sisters who always give me encouragement and motivation, the criticism of its nature build up. My spirits in my life are my two younger sisters. Vitamins are very remarkable, my cure if I'm tired. The healer when I feel life is meaningless "

The function of public speaking based on the above data is to vote and represent the organization and make decisions. That is, speakers try to vote by explaining that family support can generate optimism in the speaker. Identify the speech events in the above data as follows. Setting and scane, which is related to time and place of speech progresses. Setting the data above was held on February 14, 2018 in LPMP State University of Padang. Participant, the parties involved in the discussion on the data that his party ie participants. Ends, the intent and purpose of speech, the jury asks participants to answer the questions given. Act sequence, namely the form of speech and speech content, namely the speech between the jury and the participants are related because of questions and answers. Key, ie tone, manner and spirit when a message is delivered. In the speech 
the participants give an explanation of what things can motivate them. Instrumentalities, ie the language path used. Participant language is spoken language. Genre, ie the form of delivery. Conversations that take place in a formal atmosphere.

The above tutorials include a positive politeness strategy because it can show a sense of optimism from family support in the form of motivation. The use of this strategy can protect the speaker's self image.

Strategy 12: trying to involve the opposite of speech and speaker in a particular activity.

Can be seen in the following quotation.

What do you think you understand with effective communication? Effective communication is clear communication and does not use many additional words. The point can make our interlocutor understand the meaning being discussed.

The function of public speaking based on the above data is to vote and represent the organization and make decisions. Identify the speech events in the above data as follows. Setting and scane, which is related to time and place of speech progresses. Setting the data above held on February 17, 2018 at Ballroom Tjahaja Baru, Central Yamaha Padang road Damar No.57. Participant, the parties involved in the accounting of the data on the side of the jury and participants. Ends, the intent and purpose of speech, the jury asks participants to answer the questions given. Act sequence, namely the form of speech and speech content, namely the speech between the jury and the participants are related because of questions and answers. Key, ie tone, manner and spirit when a message is delivered. In the sentence the jury asks the participants to give answers, while the Finalist's answer to the question provides detailed answers. Instrumentalities, ie the language path used. Participant language is spoken language. Genre, ie the form of delivery. Conversations that take place in a formal atmosphere.

The above tutorials include a positive politeness strategy because participants ask questions that can be answered with reasonable logic to the other person. The use of these strategies can be used to protect the self-image of the opponent and the answer given can maintain the self-image of the opponent.

Strategy 13: give and ask the reason.

Can be seen in the following quotation.

"Assalamualaikum wr.wb.introduce I am Dedi Irawan 25 years old Finalist Mr. Tourism 2018 representative of Pasaman Barat. My daily activities as an employee at one of the private universities in Padang city. I love my work very much and I love sports and cooking so much that I join the olasport community exactly lifting weights. And I also have a culinary business".

The function of public speaking based on the above data is to vote and represent the organization and make decisions. This means that speakers introduce themselves by way of describing the activities carried out daily and other activities that can support his reputation in the event being followed.

Identify the speech events in the above data as follows. Setting and scane, which is related to time and place of speech progresses. Setting the data above was held on February 14, 2018 in LPMP State University of Padang. Participant, ie the parties involved in the speech that the data on his party that is Mr. Finalist participants. Tourism 2018. Ends, ie the intent and purpose of speech, namely that speakers' supporters can better know what are the supporting things that can be considered to advance in the next stage. Act sequence, the form of speech and the content of speech, the Finalist's speech relates to the potential possessed. Key, ie tone, manner and spirit when a message is delivered. In the speech participants confidently convey the message because it has other activities that can be used as a supporter. Instrumentalities, ie the language path used. Participant language is spoken language. Genre, ie the form of delivery. Conversations that take place in a formal atmosphere. 
The above texts include a positive politeness strategy because the speaker gives the reason why he should follow Mr. Tourism 2018. The use of such strategies may defend the speaker's public image in public.

Strategy 14: offer a reciprocal action that if the opponent says do $X$ then the opposite said will do Y.

Can be seen in the following quotation.

"I became more confident to appear in public. Getting new friends, new families, new relationships is a point that I love. My family conflicted with me since I followed the modeling world. With some demonstration and verification they finally allowed me to follow some of the activities as long as they were positive".

The function of public speaking based on the above data is to vote and represent the organization and make decisions. This means that speakers can take the positive things from the activities that are being done. Identify the speech events in the above data as follows. Setting and scane, which is related to time and place of speech progresses. Setting the data above was held on February 14, 2018 in LPMP State University of Padang. Participant, the parties involved in the accounting of the data on the party that is the Finalist or participants. Ends, the intent and purpose of speech, namely by providing proof to the family of speakers can follow the same activities in other events. Act sequence, namely the form of speech and the content of speech, the speech relating to the proof of self existence. Key, ie tone, manner and spirit when a message is delivered. In the speech the speaker conveyed energetically for having achieved some achievements. Instrumentalities, ie the language path used. Participant language is spoken language. Genre, ie the form of delivery. Conversations that take place in a formal atmosphere.

The above tutorials include a positive politeness strategy because it can maintain the speaker's self-image as evidenced by the achievements that have been achieved.

Strategy 15: give sympathy to the other person.

Can be seen in the following quotation.

"For me, plunging into the world of tourism is an effort to participate in introducing, mennjaga and preserve the culture and tourism in West Sumatera. In order to later be able to advance this country we love ".

The function of public speaking based on the above data is to vote and represent the organization and make decisions. This means that speakers express opinions. Identify the speech events in the above data as follows. Setting and scane, which is related to time and place of speech progresses. Setting the data above was held on February 14, 2018 in LPMP State University of Padang. Participant, the parties involved in the discussion on the data that his party ie participants. Ends, the purpose and purpose of speech, ie convincing others with the point of view of the speaker. Act sequence, which is the form of speech and speech content, ie the speech of the participants seeks to influence others. Key, ie tone, manner and spirit when a message is delivered. The speech is conveyed with confidence in order to persuade others. Instrumentalities, ie the language path used. Participant language is spoken language. Genre, ie the form of delivery. Conversations that take place in a formal atmosphere.

The above tutorials are included on a positive politeness strategy can give sympathy to others so that this strategy can maintain the speaker's self image.

\section{CONCLUSION}

Based on the findings and data analysis of a discussion that has been done in this research, it can be concluded that the importance of mastery of the strategy to speak to defend the public image in front of Mr. Tourism. This is because as a trusted to persuade others to be interested in visiting certain places of tourism is not an easy job. With the help of STAD type model is very aptly used to hone and train Mr. Public speaking skills. Tourism. In speaking especially in public speaking 
can be used various strategies tell to maintain self image in public. Fifteen strategies are described there is one strategy that is not suitable to be used to maintain self-image in public because it can affect the negative politeness that leads to facial threat. The strategy is a joke strategy. In its function the use of the strategy is to provide advice, give voice and represent its organization and give decision, while criticizing function is not found. The identification of speech events affects the impact of speech to be positive or negative and can protect the self-image or maintain the self image of the speaker in public.

\section{ACKNOWLEDGEMENT}

Thanks to those who have assisted in the settlement of this community based research. The parties include: campus STKIP PGRI West Sumatera; and the GKC Productions team and the Finalists. Tourism 2018.

\section{REFERENCES}

Afrinda, P. D. (2018). Turn Taking Strategy to Maintain Women `s Self Image in Peri Kopi Novel Written by Yetti A . K . A (Vol. 148, pp. 169-174). Padang: Atlantis Press. https://doi.org/http://dx.doi.org/10.2991/icla-17.2018.29

Aswandi. (2013). Belajar menjadi manusia. Yogyakarta: Ombak.

Dunar, H. (tt) My public speaking. Jakarta: Gramedia Pustaka Utama.

Widyaningrum, M.A., \& Sumarlam. (2017). Strategi kesantunan dan pelanggaran prinsip kerjasama dalam talkshow rumpi ( no secret) di trans tv (tinjauan pragmatik) 1, 2, 272-283.

Nadar, F.X. (2009). Pragmatik dan penelitian pragmatik. Yogyakarta: Graha Ilmu.

Olii, H. (2008). Public speaking. Jakarta: PT Macanan Jaya Cemerlang.

Syarief, R.M. (2005). Life excelence, menuju hidup lebih baik. Jakarta: Prestasi.

Yanda, D.P. (2018). Effect of Cooperative Learning Model Type Student Team Achievement Division ( STAD ) on Skill Understanding Poetry (Vol. 148, pp. 403-407). Padang: Atlantis Press. https://doi.org/http://dx.doi.org/10.2991/icla-17.2018.70 